\title{
Development and integration of a numerical water quality model with the geospatial application suite CIDs
}

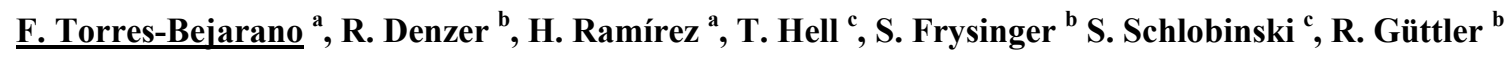 \\ ${ }^{a}$ Mexican Petroleum Institute (IMP), Eje Central Lázaro Cárdenas 152 Mexico D.F., Mexico \\ ${ }^{b}$ Environmental Informatics Group (EIG), Goebenstrasse 40, 66117 Saarbrücken, Germany \\ ${ }^{c}$ Cismet GmbH, Altenkesseler Strasse 17, 66115 Saarbrücken \\ Email:fmtorres@imp.mx
}

\begin{abstract}
Environmental Information Systems (EIS) have become in very important tool for their capacity of manipulating huge amounts and heterogeneous types of data, and for their capacity to integrate different technologies in a single computational tool.

The need of appropriate tools for diagnosis and increasingly accurate ecosystems forecasts, require developing strategies that take into account the largest possible number of environmental variables and consider the time variation of the studied phenomenon. However, it is a challenge to apply these tools to comprehensive studies in water systems, including the use of hydrodynamic models, contaminant transport and Geographic Information Systems (GIS) coupled.
\end{abstract}

Taking advantage of EIS for resource management linking GIS with traditional mathematical modelling have become in an attractive idea. One of the biggest attractions of research in environmental modelling and its integration within environmental information systems or environmental decision support systems lies in its essentially applied nature. Two main lines in applications may be distinguished: emergency planning (intended to organize a disaster response), and diagnosis and general environmental assessment (trying to avoid or prevent catastrophic events). For this reason, the main objectives of this work were: first, to develop a water quality model to evaluate the hydrodynamics and contaminant transport in rivers, solving the twodimensional Saint Venant and Advection-Diffusion-Reaction equations to calculate the river hydrodynamics and the contaminant transport, respectively, and secondly, integrate the developed numerical model into a user friendly EIS, to allow an easy use and application of the tool by water managers.

Finally, a tool specifically tailored to the downstream area of the Coatzacoalcos River, with capacity of hydrodynamic and water quality modelling, environmental analysis and management of massive information through GIS was built for environmental assessment, specifically concerning water quality studies. The application to the Minatitlan-Coatzacoalcos Industrial Park in Mexico is presented, where good results were obtained from the modelling carried out by the designed EIS.

The general idea was to provide a tool for decision makers and environmental and water resources managers, which facilitate the evaluation work and the decision-control process. While tools such as environmental indices, GIS, and numerical models are individually adequate for evaluation process and also have been extensively tested, the possibility of implementing it in a fully integrated EIS, as the proposed in this work, which consists of the integrated numerical model to capture the river's hydrodynamics and water quality evaluation, and the software incorporating the decision support logic, including the GUI, magnifies its effectiveness in all respects, for information manipulation, data and results analysis, creation of new and different scenarios, and the visualization based on GIS, allows a comprehensive environmental assessment of rapid response.

The system was built in a collaboration of the Mexican Petroleum Institute (IMP), Environmental Informatics Group and cismet $\mathrm{GmbH}$ and is based on the geospatial application suite cids of cismet. The system integrates several tools and models into a holistic, user-centered application.

Keywords: Decision Support System (DSS), Coastal Catchment Initiative (CCI), water quality 


\section{INTRODUCTION}

It is well known that in decision-making and environmental management, the information availability is essential. But, more important is the state of the information available, because usually the information is scattered and/or poorly understandable.

Water managers have short deadlines imposed by legislation, because politicians generally want simple concepts and seek compatible methods for determining the impact of their decisions. In contrast, scientists are driven by innovation and understanding reached during long periods of study that can be replicated by their peers. The results of scientific studies are not always in the form required by water managers, leaving substantial judgments in making final decisions (Acreman, 2005).

The need of appropriate tools for diagnosis and increasingly accurate forecasts of ecosystems, require developing strategies that take into account the largest possible number of environmental variables and consider the variation time of the studied phenomenon (Jakeman y Letcher, 2003). However, it is a challenge to apply these tools to comprehensive studies of water systems, including the use of hydrodynamic models, contaminant transport and geographic information systems coupled.

In this work, a computational tool that integrates the latest technology to handle, process and assess environmental information in a comprehensive manner has been developed. This EIS integrates a set of mathematical models that work as a tool of strategic planning and allows users to carry out water quality assessment and wastewater discharges management, to assist the water pollution control and prevention, being able to analyze different scenarios and contribute to the best possible practices and improved pollution control and investigation.

\section{THE INDUSTRIAL PARK MINATITLAN-COATZACOALCOS}

Coatzacoalcos is a commercial and industrial port that offers the opportunity to operate a transportation corridor for international traffic, the site is the development basis for industrial, agricultural, forestry and commercial enterprise in this region; by the volume of cargo it is considered the third largest port in the Gulf of Mexico. The area of Coatzacoalcos river mouth has had a rapid urban and industrial growth in the last three decades. In this area, the largest and most concentrated industrial chemical complex, petrochemical and derivatives has been developed in Latin-America. The importance of this industrial park, formed mainly by the Morelos petrochemical complex, Cangrejera, Cosoloacaque and Pajaritos, is such that $98 \%$ of the petrochemicals used throughout the country are produced there. Figure 1 shows the study zone location.

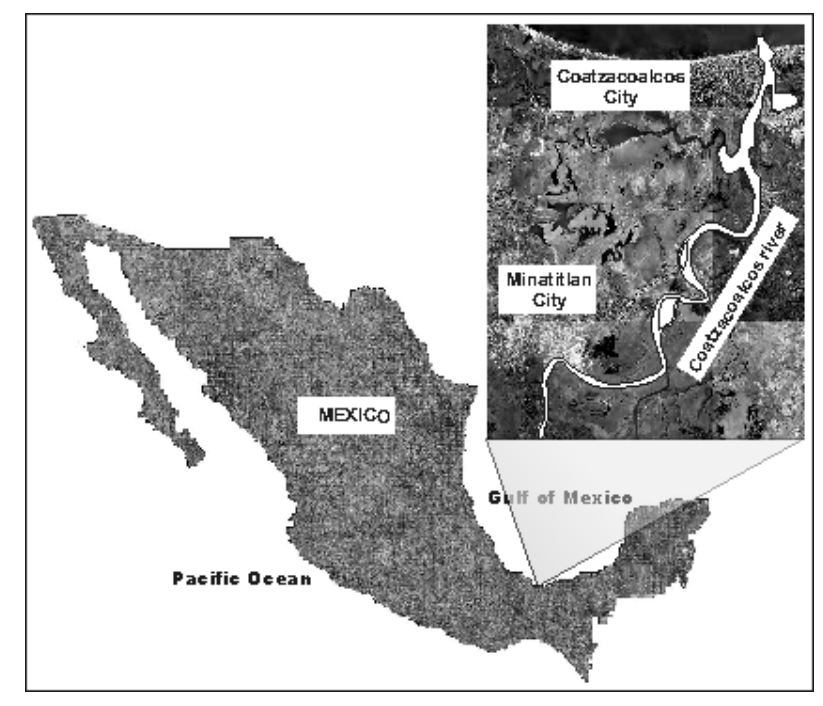

Figure 1. Coatzacoalcos River and study zone.

\section{SYSTEM OVERVIEW}

The first part of the work was based on the numerical model development for transport, transformation and reaction of contaminants associated with the oil industry. The developed model is a scientific numerical hydrodynamic and water quality model written in FORTRAN; the model has been named ANAITE/2D (Torres-Bejarano and Ramirez, 2007). The current version of this model solves the two-dimensional SaintVenant equations for hydrodynamics and the advection-diffusion-reaction (ADR) equation for transport and transformation of pollutants; with the ADR equation five modules were set grouping variables according to their origin: physical, chemical-biological, eutrophication, metals and PAHs. Also, a Water Quality Index that integrates all the pollutants studied and represents the state of water quality in a single value was developed, with the intention of making the interpretation easier for the system users. 


\subsection{The hydrodynamic module}

The hydrodynamics is simulated by applying the two-dimensional Saint Venant equations (1, 2 and 3); these equations describe two-dimensional unsteady flow vertically averaged, representing the principles of conservation of mass and momentum and are obtained from the Navier-Stokes-Reynolds equations under several simplifications. The Saint Venant equations in non-conservative and simplified form are:

$$
\begin{aligned}
& \frac{\partial h}{\partial t}+\frac{\partial(h u)}{\partial x}+\frac{\partial(h v)}{\partial y}=0 \\
& \frac{\partial u}{\partial t}=-u \frac{\partial u}{\partial x}-v \frac{\partial u}{\partial y}-g \frac{\partial h}{\partial x}+v_{t}\left(\frac{\partial^{2} u}{\partial x^{2}}+\frac{\partial^{2} u}{\partial y^{2}}\right)+g\left(S_{o x}-S_{f x}\right) \\
& \frac{\partial v}{\partial t}=-u \frac{\partial v}{\partial x}-v \frac{\partial v}{\partial y}-g \frac{\partial h}{\partial y}+v_{t}\left(\frac{\partial^{2} v}{\partial x^{2}}+\frac{\partial^{2} v}{\partial y^{2}}\right)+g\left(S_{o y}-S_{f y}\right)
\end{aligned}
$$

where:

$$
\begin{aligned}
S f & =\text { friction slope, }[\cdot] \\
h & =\text { water depth, }[\mathrm{m}] \\
u & =\text { longitudinal velocity, } \mathrm{x} \text { direction, }[\mathrm{m} / \mathrm{s}] \\
v & =\text { transversal velocity, } \mathrm{y} \text { direction, }[\mathrm{m} / \mathrm{s}] \\
v_{t} & =\text { turbulent viscosity, }\left[\mathrm{m}^{2} / \mathrm{s}\right] \\
g & =\text { acceleration due to gravity, }\left[\mathrm{m} / \mathrm{s}^{2}\right] \\
x, y, z & =\text { variables of the coordinate system }
\end{aligned}
$$

\subsection{The water quality module}

This module allows the behaviour simulation and concentration distributions for different water quality parameters that can be individually represented or gathered in a water quality index (WQI) programmed within the model. The water quality module solves the following parameters, grouped according to the chemical properties (Figure 2):

- Physics: Temperature, Salinity, Suspended Solids, Electric Conductivity;

- Biochemical: Dissolved Oxygen, Biochemical Oxygen Demand, Fecal Coliforms;

- Eutrophication: Ammonia Nitrogen, Nitrates, Organic Nitrogen, Inorganic phosphorous (phosphate), organic Phosphorous

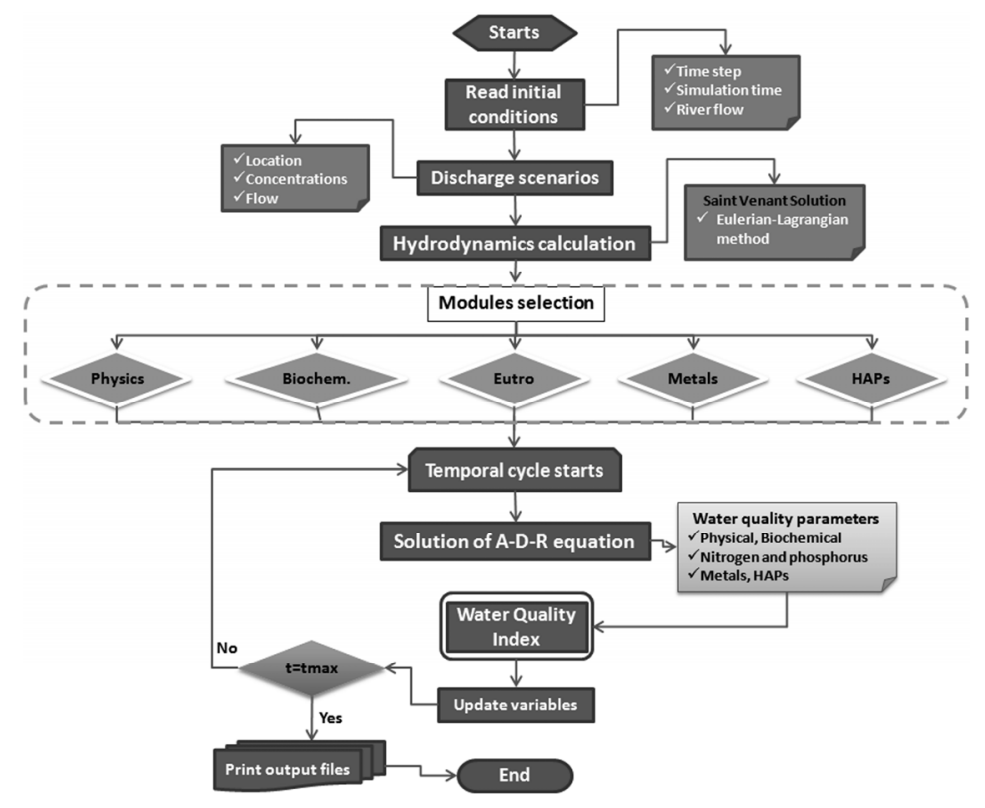

The transport and transformation of the different environmental parameters was carried out by applying the two-dimensional approach of $\mathrm{ADR}(4)$ :

Figure 2. Flow diagram of ANAITE/2D numerical model. 


$$
\frac{\partial C}{\partial t}+U \frac{\partial C}{\partial x}+V \frac{\partial C}{\partial y}=\frac{\partial}{\partial x}\left(E x \frac{\partial C}{\partial x}\right)+\frac{\partial}{\partial y}\left(E y \frac{\partial C}{\partial y}\right) \pm \Gamma_{C}
$$

where:

$$
\begin{aligned}
& C=\text { Concentration of any water quality parameter, }(\mathrm{mg} / \mathrm{L}) \\
& E x=\text { Coefficient of longitudinal dispersion, }\left(\mathrm{m}^{2} / \mathrm{s}\right) \\
& E y=\text { Coefficient of transversal dispersion, }\left(\mathrm{m}^{2} / \mathrm{s}\right) \\
& \Gamma c=\text { Reaction mechanism (specific for each parameter), }\left(\mathrm{m}^{-1}\right)
\end{aligned}
$$

The reaction mechanism $\Gamma \mathrm{c}$, is used to represent the water quality parameters, and it is solved individually for each of them.

\subsection{Water quality index}

A module which calculates the water quality index that integrates physical, chemical variables and toxic substances (metals and hydrocarbons) is included. The information required for its calculation comes from the water quality modules described previously, which provides information on the water quality for any time and place of the aquatic system.

Equation (5) is used to calculate the WQI. This index was designed specifically for rivers affected by the oil and chemical industry as essential part of the model. The objective of this index is to determine whether the use of a water body affected by the oil industry activities, is suitable for public supply, protection of aquatic life and irrigation.

$$
I C A=\frac{\sum_{i=1}^{n} I_{i} \times w_{i}}{\sum_{i=1}^{n} w_{i}}
$$

where:

$$
\begin{aligned}
& I_{i}=i t h \text { index of principal components } \\
& w_{i}=\text { specific weight assigned to the principal components }
\end{aligned}
$$

\subsection{Numerical solutions and validation}

The Saint Venant and ADR equations were numerically solved using an Eulerian-Lagrangean method. The solution separates the equations by its main components: advection and diffusion, which are solved using a combination of Lagrangian and Eulerian techniques, respectively. In this way, the entire equations are solved.

For validation purpose, a sampling and measurement campaign was carried out in the Coatzacoalcos river stretch from upstream of Minatitlan city $\left(17^{\circ} 57^{\prime}\right.$ $\left.00^{\prime \prime} \mathrm{N}-94^{\circ} 33^{\prime} 00^{\prime \prime} \mathrm{W}\right)$ to its mouth in Gulf of Mexico $\left(18^{\circ} 09^{\prime} 32^{\prime \prime} \mathrm{N}-94^{\circ}\right.$ 24 ' 41.33" W). The main objective was to obtain velocities, bathymetry and water quality at 10 points of the Coatzacoalcos River. The information obtained through direct measurements and chemical analysis is primarily used for testing and numerical model validation. When compared with field measurements, we observed that the model results are consistent with these measures and they are in the same order of magnitude. Figure 3 shows the comparison for some of the water quality results. The $\mathrm{X}$ axis represents a relative position. For this case is the profile along the river centerline.
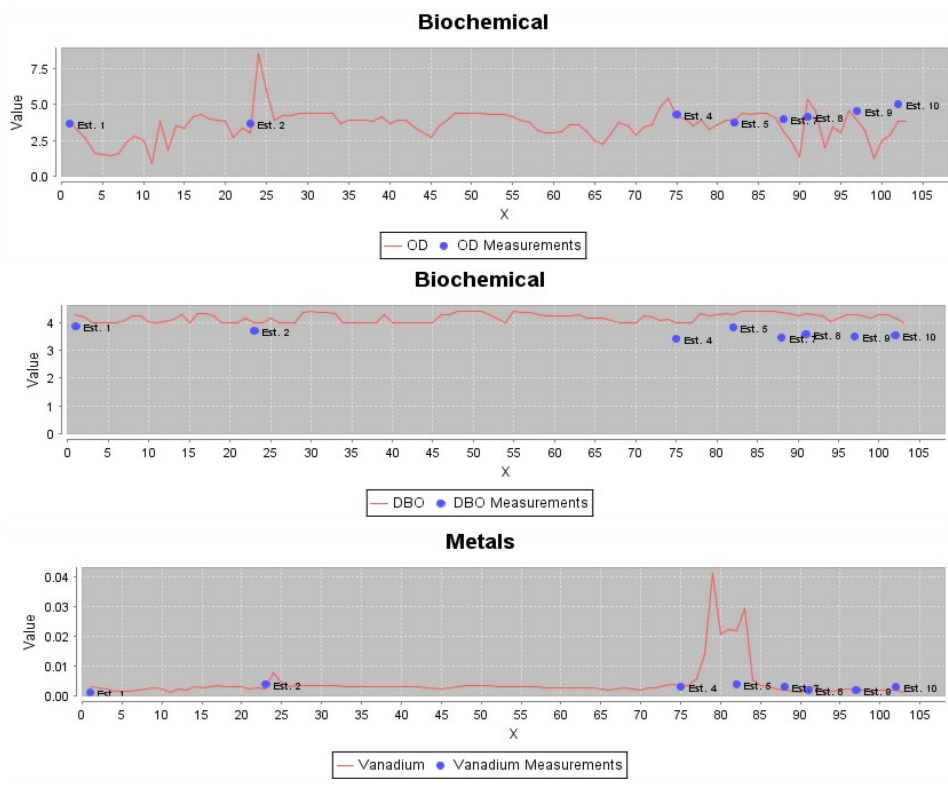

Figure 3. Concentration profiles for measured and calculated DO, BOD and Vanadium. 


\section{TECHNOLOGIC PLATFORM (CIDS)}

Software implementations are implemented using CIDs ${ }^{\circledR}$ Navigator, developed by the Environmental Informatics Group (EIG-CISMET) (Denzer, 2005; Güttler et al., 2000). It is a simple and powerful tool for geospatial data manipulation of complex processes, is an independent platform that can be used on all common operating systems, which in combination with new and innovative environmental information technologies the maximum benefit of computational advances can be get. The system is based on a concept of distributed service that integrates GIS, models, and data management/metadata, and interconnection with other systems.

Numerical model simulations for water quality are performed within the CIDs platform, which was specifically adapted to integrate and implement the numerical model, allowing selection of the different modules and processes to simulate the pollutant transport and water quality. To integrate the numerical model with CIDs a series of steps required to develop the final tool were carried out. The steps involved include: Software engineering, conceptual model design, technology selection, geo-informatics and final product.

\subsection{System components}

This EIS is designed for general users who want to use the system for analysis, simulation and recognition of the study area and decision makers who want to simulate real-world scenarios in the studied Coatzacoalcos River reach. The EIS will eventually have three key players and a cooperative system. General users and expert users access the system through Internet with specific limitations; the system Manager has full access, this allows updating the model, databases and files modification. The first version of this system (which is the prototype here presented), supports only access the Administrator and primary user.

\subsection{Architecture of EIS-ANAITE/2D}

The system architecture integrates essential elements such as database management, GIS and models, constituted by the conceptualization of service-oriented architecture (SOA). The proposed architecture consists basically of two main modules: Client and Service (Figure 4).

Client. Users access the EISANAITE/2D through a Web site using any standard Web browser (Internet Explorer, Firefox, Google Chrome, etc.). Since the current version is a prototype, the system is configured to be used locally, therefore must be configured on a local network. From the Web site, CIDs Navigator is started, which integrates the interfaces where the users configure and enter the initial data required to run the numerical model and the results are displayed. Besides Web technology, the system also requires Java Runtime Environment (JRE) to be installed and executed.

Web Service. The main objective of this module is the numerical model execution. This service runs on Axis2 service, which is an open-source implementation of SOAP or Web services container, implemented in TOMCAT. SOAP allows a program

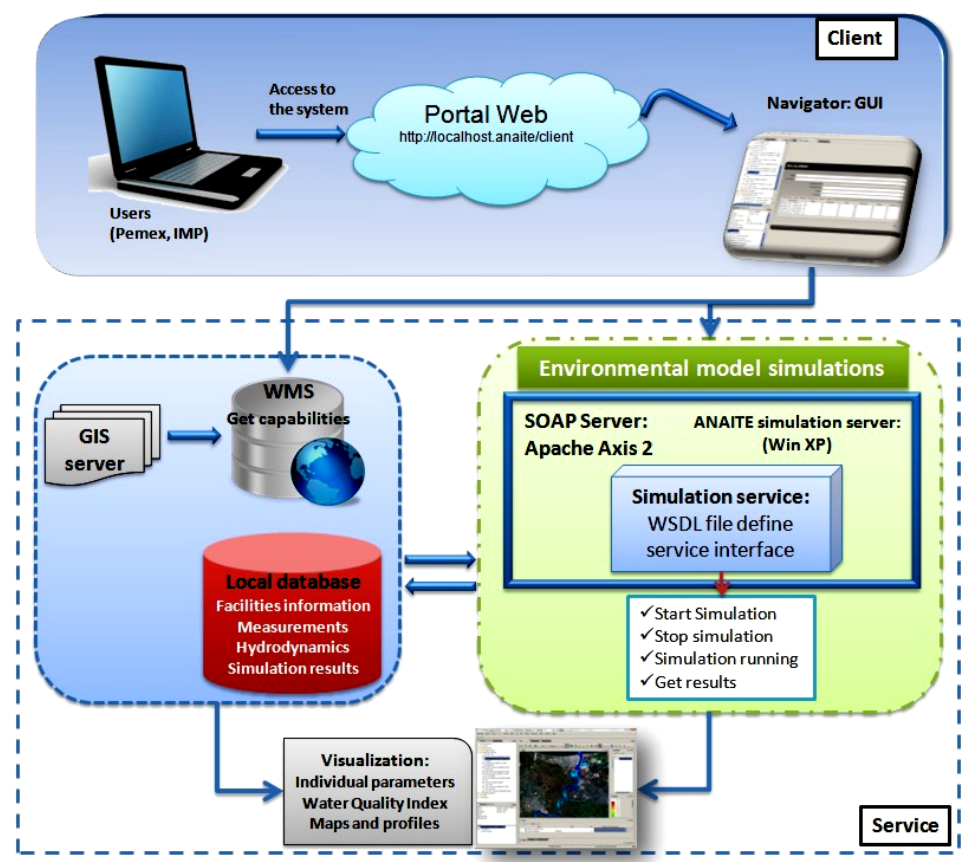

Figure 4. System architecture. running on one type of operating system (e.g. Windows XP), communicate with another program running on the same or different operating system (e.g. Linux), which is the way how the information system developed operates. Using a WSDL file (Web Services Description Language) the service interface is defined, using 
XML messages that the service can accept and return, sending the instructions to the numerical model. These are: start and stop simulation, simulation still running, get results.

\subsection{System description and operation}

The EIS-ANAITE/2D incorporates a GIS-based interface that allows a friendly access, flexible and easy to implement user-defined scenarios. All user communication with the services is carried out by means of this interface, either for input data and maps and numerical model visualisation. Almost all features may be accessed via mouse click. The main screen is divided into different areas, being the most important: Maps area, Description area, Objects catalogue and Data Source area (Figure 5). The Data Source area is used to connect the system to external data servers and maps WMS or WFS type. On the Map Area is possible to overlay different maps (layers) and display the model results.

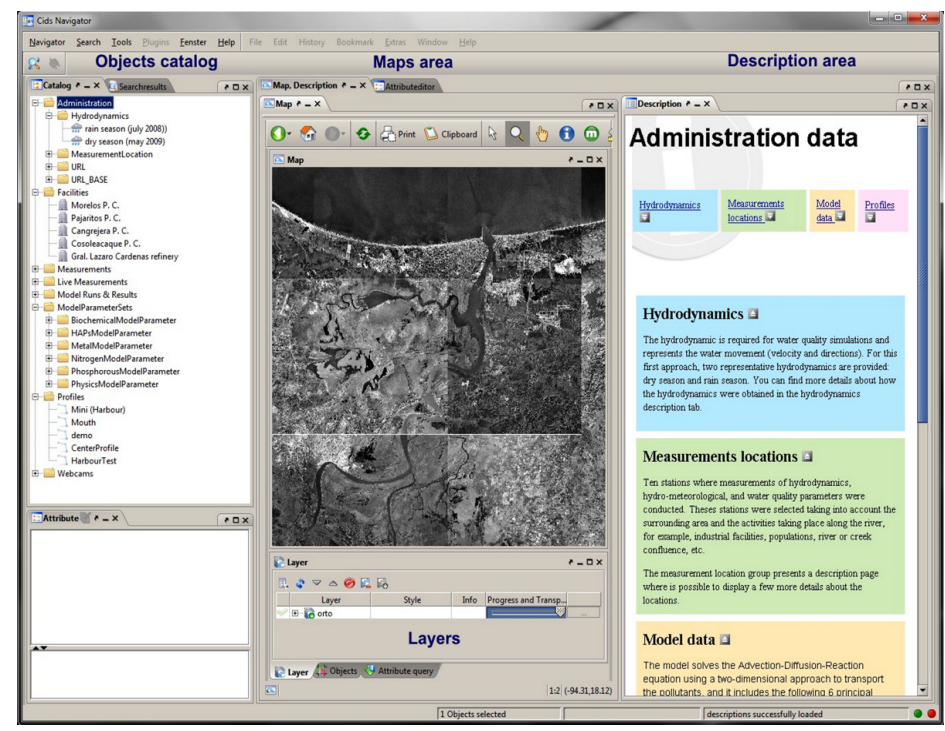

Figure 5. Main screen of EIS-ANAITE/2D.

\subsection{Model configuration}

To run the water quality model within the EIS, an initial water quality sub-module selection is required, which is done through an interface designed for that purpose. Each module includes all the parameters described in Section 3.2. The river geometry and bathymetry is already loaded in the system, however the information to be provided related to the discharge is as follows:

- Location and position of discharges in the river,

- Volume discharged (flow rate),

- Chemical characterization (parameters concentration),

- General description to identify the discharge conditions.

The following inputs are required to run the model:

- Water quality module selection. Can be selected individually or all together.

- Hydrodynamics, represented by a specific month of the year.

- Simulation time. Is the total time to be simulated, ranging from 130 days.

- Time step. The time that passes in the model before the variables are updated (s).

- Flow rate. Amount of water that flows through the river in a given time $\left(\mathrm{m}^{3} / \mathrm{s}\right)$.

The system store the model configuration as well as the model parameters sets, which allows reusing the information at any time.

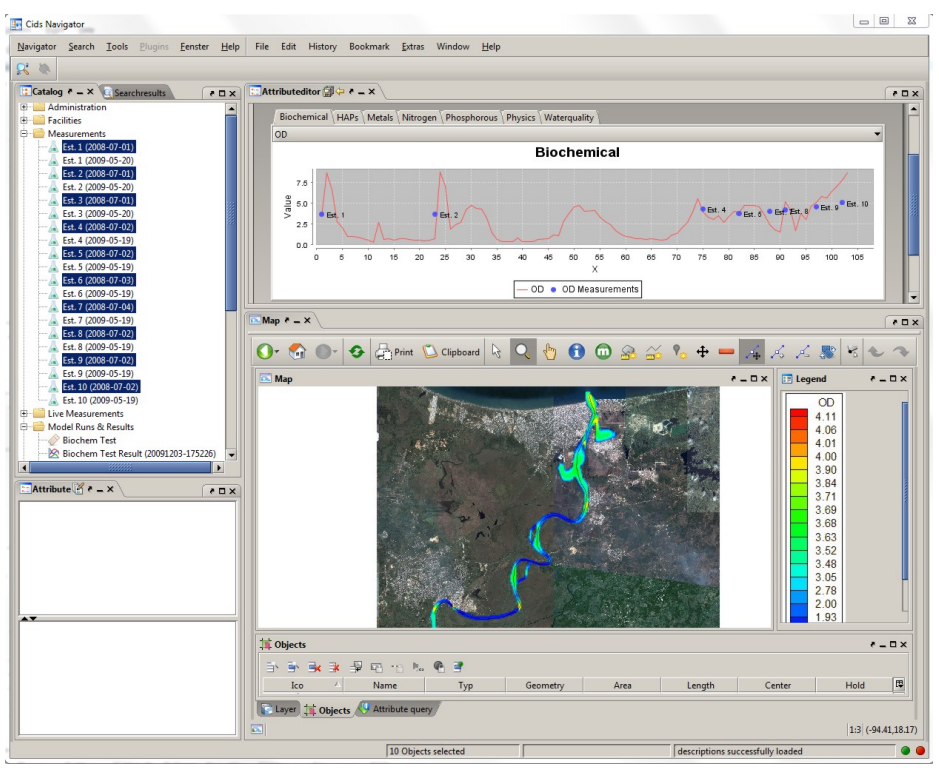

Figure 6. Results visualisation in EIS-ANAITE/2D. 


\subsection{Output and results visualisation}

In the Map Area is possible to overlay different maps (layers) simultaneously, and apply transparency to observe and compare different characteristics of the surrounding area. The Data Source area is used to connect the system with external data sources and maps. A data source can be a Web Map Service (WMS) or Web Feature Service (WFS) available through the Web, being able to visualize specific details of the study area and compare them with the simulation scenarios and model results. The system also allows the results visualisation in two ways: as profiles (X-Y graphs) and as maps or concentration maps (Figure 6 and 7).

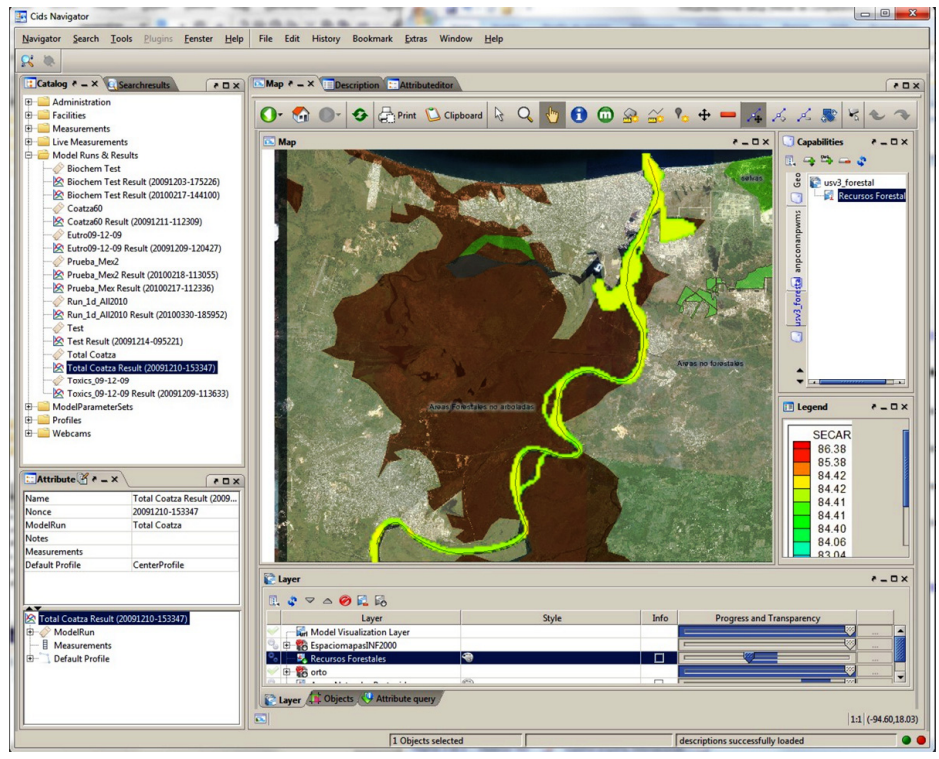

Figure 7. WQI visualisation.

\section{DISCUSSION AND CONCLUSIONS}

We have developed a numerical model that solves the two-dimensional Saint Venant equations and the Advection-Diffusion-Reaction equation to study the pollutants transport and water quality in Coatzacoalcos River, Mexico, solving 22 different parameters, among physical, chemical, biological and toxic substances, being aggregated in a water quality index, which is a useful and understandable tool by managers and decision makers. All these evaluation tools were integrated within CIDs, which is a state-of-the-art EIS, using its graphical interface to perform with great simplicity all necessary actions to configure and run the model and display the results using geographic information systems.

The model results showed good agreement with water quality parameters measured in the river. Therefore, it is considered that this system can be implemented and applied to different situations and discharge scenarios for the studied area.

The EIS-ANAITE/2D can be implemented by heterogeneous type of users, for example biologists, environmental engineers, water managers, or even people barely familiar in this fields, as politicians, lawyers, economists and general public.

\section{ACKNOWLEDGMENTS}

EIG and CISMET Team: Dr. Reiner Güttler, Sebastian Puhl, Thorsten Herter, Martin Scholl, Benjamin Friedrich, Michael Brill, Nils Steinbiß. Mexican Petroleum Institute: All the staff of the Posgraduate Studies Program

\section{REFERENCES}

Acreman, M. (2005). Linking science and decision-making: features and experience from environmental river flow setting. Environmental Modelling \& Software 20 (2005) 99-109

Denzer, R. (2005). Generic integration of environmental decision support systems - state-of-the-art. Environmental Modelling \& Software 20 (2005) 1217-1223. DOI:10.1016/j.envsoft.2004.09.004.

Güttler, R., Denzer, R., and Houy, P. (2000). An EIS called WuNDa. Environmental Software Systems, Environmental Information and Decision Support, vol. 3. Kluwer Academic Publishers, pp. 114-121.

Jakeman A.J. y Letcher R.A. (2003). Integrated assessment and modelling: features, principles and examples for catchment management. Environmental Modelling \& Software 18 (2003) 491-501. DOI: 10.1016/S1364-8152(03)00024-0. 
Torres-Bejarano FM, Ramírez H. (2007). El programa ANAITE para el estudio de la dinámica y la calidad del agua en cauces naturales con pendiente suave. Revista Internacional de Contaminación Ambiental 23 (3) $115-127$. 